\title{
Histomorphometric study of the follicles of the ovary in Bangladeshi women
}

\author{
Hosna Ara Perven ${ }^{1}$, Abu Sadat Mohammad Nurunnabi², Shamim Ara ${ }^{3}$
}

\begin{abstract}
Background: The accurate assessment of size and number of ovarian follicles are paramount to understanding the physiology of female reproduction. Objective: To observe the variation in size of the Graafian follicle and follicular number with age in Bangladeshi women. Methods: This descriptive type of study was done in the Department of Anatomy, Dhaka Medical College, Dhaka, from January to December 2009, on 140 post mortem human ovaries collected from 70 unclaimed female dead bodies from the morgue of Forensic Medicine, Dhaka Medical College, Dhaka. The samples were divided into three age-groups including group A (10-13 years), group B (14-45 years) and group C (46-52 years). 10 best prepared histological slides from 14-45 years age group were examined to determine the average size of Graafian follicle and 20 slides from each group were taken to determine the number of follicles. Results: The average diameter of the Graafian follicles of the right is slightly higher than that of the left ovary but not statistically significant $(\mathrm{p}>0.05)$. No difference was found in follicular number in between the right and the left ovaries at any age group. However, the difference in number of the follicles of the ovary were statistically significant in between age groups A \& $\mathrm{C}$ and $\mathrm{B} \& \mathrm{C}(\mathrm{p}<0.001)$. Conclusion: The average diameter of Graafian follicle was found greater in the right ovary than the left ovary. However, the number of ovarian follicles was found to decrease in old age.
\end{abstract}

Key words: Histomorphometry, ovarian follicle, Graafian follicle, human ovary.

J Bangladesh Soc Physiol. 2012 December; 7(2): 89-93

For Authors Affiliation, see end of text.

http://www.banglajol.info/index.php/JBSP

\section{Introduction}

$\bigcap$ he ovaries are the primary female reproductive organs with functions of production and ovulation of oocytes and production and secretion of ovarian hormones like oestrogens and progesterone ${ }^{1}$. Ovarian reserve and reproductive age may be determined from measurement of the number of follicles ${ }^{2}$. The accurate assessment of ovarian reserve will bring revolution in the management of women requesting assisted conception or those who have had treatment for childhood cancer and those who are considering delaying

Received: May 2012; Accepted : September 2012 a family for personal or professional reasons ${ }^{3}$. Besides, the determination of follicular numbers within the primate (e.g. human, apes etc.) ovary is paramount to understanding the physiology of reproductive aging 4 . The reproductive lifespan is ultimately determined by the number of ovarian non-growing follicles (NGF). Therefore, accurate and efficient methods for estimating the number of NGF are also paramount for investigation into the ovarian aging process ${ }^{3}$. Hence, the study of the follicular numbers can provide also important information about the function of the ovary, particularly in the 
relationship between folliculogenesis and the factors that regulate $\mathrm{it}^{5}$. By knowing the diameter of Graafian follicle, a physiological or pathological cyst can be assessed ${ }^{6}$. Disease can be defined and measured only in terms of deviation from normal structure and function. Hence, a clear conception and population data of the ovarian follicles is a prerequisite for the diagnosis and treatment of the ovarian disease ${ }^{7}$. Ovarian function related clinical conditions such as infertility, non-neoplastic follicular cyst and ovarian malignancy are common in our country ${ }^{8}$. Moreover, it has been observed by reviewing the literature and the texts that several histomorphometric studies have been done on the ovarian follicles in foreign countries, whereas proper attention has not been given in our country ${ }^{9}$. Therefore, the present study was designed to observe the variation in the size of the Graafian follicle and follicular number with age in Bangladeshi women. The results of the present study can be used as a potential reference for the measurement of ovarian follicles of Bangladeshi women and to determine the abnormal evidences in forensic and pathologic corpses.

\section{Methods}

A descriptive type of study was designed and done in the Department of Anatomy, Dhaka Medical College, Dhaka, from January to December 2009, based on collection of 140 intact human ovaries from 70 unclaimed female dead bodies with age range 12-52 years. The age was noted down from the morgue's record book in the Department of Forensic Medicine, Dhaka Medical College, Dhaka. All the samples were collected within 24-36 hours of death without any sign of putrefaction and taken from medicolegal cases excluding poisoning, any cutting or crushing injury to the ovary, ovary found in one side and diseased ovaries. This study was approved by the Ethical Review Committee of Dhaka Medical College, Dhaka.
The ovary was taken out from cadaver by dissection and its outer surface was dried with blotting paper and fixed in $40 \%$ formalin solution. After isolation, the samples of ovaries were divided into three age-groups comprising group A (10-13 years), group B (14-45 years) and group C (46-52 years), according to Kumar and Malhotra $^{10}$ (Table I).

For preparation of the slide, tissue blocks were fixed in $10 \%$ formol saline in a plastic container. The tissues were washed in running tap water, dehydration was done with ascending grades of alcohol, cleared with xylene, infiltrated and embedded in paraffin. Paraffin blocks were cut at $5 \mathrm{~mm}$ thickness and were stained with routine Harris' Haematoxylin and Eosin (H \& E). The light compound microscope which was used for the microscopic measurement was OLYMPUS CHB, made in Tokyo, Japan.

For measurement of the average diameter of Graafian follicle, 10 best prepared slides were taken ( 5 of right ovary and 5 of left ovary) from Group B (14-45 years) and examined under the light microscope in low magnification (' 10 objectives, ' 10 eyepiece). At first, a Graafian follicle was identified. Then the diameter of the Graafian follicle was measured by using the ocular micrometer and stage micrometer. Two measurements were taken for each Graafian follicle. One measurement was taken at the maximum transverse diameter of follicle (Figure 1) and another at perpendicular to the first one. Hence, the transvertical diameters of the follicles were measured by taking the mean of the two diameters i.e. (Maximum transverse diameter + Maximum perpendicular diameter $) \div 2$

The stage micrometer calibration was focused under the objective to be used and the ocular micrometer calibration was superimposed on them in such a way that starting mark on the ocular micrometer matched exactly with a starting mark on the stage micrometer. Then the markers on the stage and ocular micrometer that corresponds to each other most closely were 
noted. In this way determination of how many of the smallest division of the ocular micrometer corresponds to how many smallest division of the stage micrometer was done (according to Nurunnabi et al. $)^{11}$. The diameter was determined in $\mathrm{mm}$ and converted into $\mathrm{mm}$.

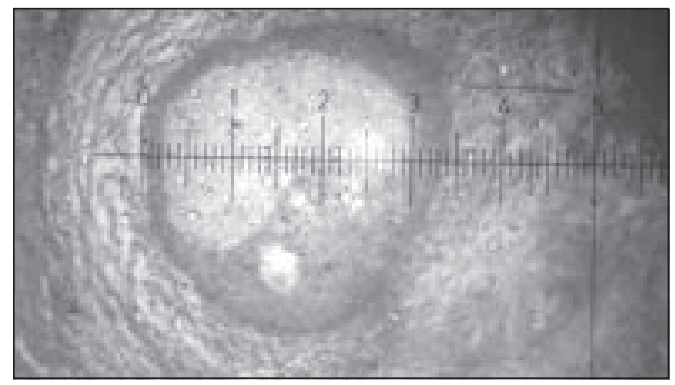

Figure 1. Photomicrograph of the ovary taken from 14-45 years age group showing the measuring procedure of the diameter of the Graafian follicle by using the ocular micrometer (' 10 objectives, ' 10 eyepiece) $(\mathrm{H}$ \& E stain).

For measurement of the total number of the ovarian follicles per sq. mm. area of the microscopic field, 20 best prepared slides were taken (10 of right ovary and 10 of left ovary) from each group and examined under the light microscope in low magnification (' 10 objectives, ' 10 eyepiece). The stained tissue section on the slide was divided into three equal parts by a computer generated, photographically produced equal sized room over a transparent plastic sheet by drawing three lines which radiated from the centre towards the periphery at 10 o'clock, 2 o'clock and 6 o'clock position. Then, this sheet was fixed on the top of the cover slip by an adhesive tape. The centre of this sheet corresponded with the centre of the tissue section. From each triangular area, one microscopic field was selected near the centre for study. Thus from each slide, three different fields were chosen for counting the number of ovarian follicles. Therefore, from each group 90 fields were taken for the study. The counting was done within a counting circle specially devised for this purpose. A counting circle of $5 \mathrm{~mm}$ diameter was printed on a transparent plastic sheet, which was cut to fit into the eyepiece of the light microscope. Thus a black circular outline was superimposed over the actual microscopic field. The circle encircled few whole of the ovarian follicles, while other ovarian follicles were also included partially (one-half, onefourth, three-fourths etc.) inside that counting circle. However, the rest of the follicles were also seen. Considering this circle as the field to be studied (rather than the whole microscopic field), the portions of the follicles inside this field were taken in consideration by an eye estimate e.g. 1, $0.75,0.5,0.25$ etc. From the three counts of three different fields of each slide, an average count was calculated for each slide. Thus the average counts of 90 fields for each group were available. The count was then converted into number per square $\mathrm{mm}$ by conversion measurement by means of an ocular micrometer and a stage micrometer (according to Nurunnabi et al.) ${ }^{11}$.

Data were expressed as mean \pm SE. The comparison between right and left ovary was done by unpaired Student's ' $t$ ' test and the comparison between different age groups was done by One-way ANOVA. All the statistical analyses were done by using the SPSS 13.0 version.

\section{Results}

The mean \pm SE diameter of the Graafian follicle was $12.90 \pm 4.01 \mathrm{~mm}$ in the right ovary and $12.40 \pm 3.92 \mathrm{~mm}$ in the left ovary. The difference in mean diameter of Graafian follicle was statistically not significant in between the right and the left ovary ( $\mathrm{p}>0.05$ ) (Figure 2). As Graafian follicle was found only in 14-45 years age group, the difference between groups was not observed.

The mean \pm SE number of the follicles of the right ovary per square $\mathrm{mm}$ area of the microscopic field was $55.87 \pm 7.82$ in $10-13$ years age group, $81.96 \pm 5.25$ in $14-45$ years age group and $28.42 \pm 5.50$ in $46-52$ years age group. The mean number of the follicles of the left ovary per square $\mathrm{mm}$ area of the microscopic field was $54.07 \pm 7.78$ in 10-13 years age group, $80.34 \pm 4.83$ in $14-45$ years age group and $26.95 \pm 5.60$ in $46-52$ years age 


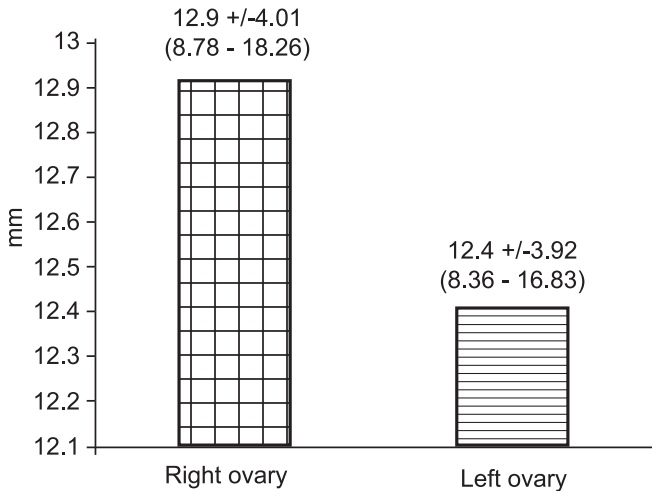

Figure 2: Diameter of Graafian follicles ( $\mathrm{mm}$ ) of right and left ovary in 14-45 years age group (reproductive age group) (Figures in parentheses indicate range).

group. The difference in number of the follicles was not statistically significant in between the right and the left ovaries (Table I). However, the difference in number of the follicles of the ovary were statistically significant in between A \& C and B \& C age groups $(\mathrm{p}<0.001)$ (Table I).

Table I: Number of follicles of right and left ovary in different age group

\begin{tabular}{lccl}
\hline Group & \multicolumn{2}{c}{ Number of follicles per $\mathrm{mm}^{2}$} & P value \\
& Right ovary & Left ovary & \\
& Mean \pm SE & Mean \pm SE & \\
\hline A & $83.40 \pm 4.89$ & $81.75 \pm 5.16$ & $>0.50^{\text {ns }}$ \\
$(\mathrm{n}=20)$ & $(76.39-89.12)$ & $(74.30-87.57)$ & \\
$\mathrm{B}$ & $81.96 \pm 5.25$ & $80.34 \pm 4.83$ & $>0.50^{\text {ns }}$ \\
$(\mathrm{n}=20)$ & $(73.84-87.35)$ & $(72.84-85.47)$ & \\
$\mathrm{C}$ & $28.42 \pm 5.50$ & $26.95 \pm 5.60$ & $>0.50^{\text {ns }}$ \\
$(\mathrm{n}=20)$ & $(20.37-35.40)$ & $(18.82-34.25)$ & \\
& $\mathrm{P}$ value & $\mathrm{P}$ value & \\
A vs B & $>0.50^{\text {ns }}$ & $>0.50^{\mathrm{ns}}$ & \\
A vs C & $<0.001^{* * *}$ & $<0.001^{* * *}$ & \\
B vs C & $<0.001^{* * *}$ & $<0.001 * * *$ & \\
\hline
\end{tabular}

Figures in parentheses indicate range. Comparison between the right $\&$ the left side done by unpaired student's ' $t$ ' test and in between different age group were done by One way ANOVA (PostHoc), ns = not significant, $* * *=$ significant.

Group A: $10-13$ years,

Group B: $14-45$ years

Group C: $46-52$ years

\section{Discussion}

Different investigators reported varying size of mature ovarian follicle. Copenhaver, Kelly and Wood $^{12}$ stated that the average diameter of Graafian follicle is $10-15 \mathrm{~mm}$. Bhatla ${ }^{13}$ stated that a ripe follicle is $5-8 \mathrm{~mm}$. in diameter, and may reach 16-24 mm. immediately before rupture, and is visible to the naked eye. According to Fawcet ${ }^{14}$, its diameter ranges from 15 to $20 \mathrm{~mm}$. at the time of ovulation. Junqueira and Carneiro ${ }^{15}$ stated that the diameter of Graafian follicle is $2.5 \mathrm{~cm}$. Ross and Pawlina ${ }^{16}$ stated that its diameter is $10 \mathrm{~mm}$. or more. Healy ${ }^{7}$ stated that the average diameter of Graafian follicle is $2 \mathrm{~cm}$. The diameter of the Graafian follicles of present study are in agreement with that of Copenhaver, Kelly and Wood $^{12}$ and Ross and Pawlina ${ }^{16}$. However, the findings of Bhatla ${ }^{13}$, Fawcet ${ }^{14}$, Junqueira and Carneiro $^{15}$ and Healy ${ }^{7}$ are much higher than that of the present study, which could be due to racial variation. No published data was found regarding the diameter of the Graafian follicle in Bangladesh.

Forabosco et al. ${ }^{17}$ studied 5 left neonatal ovaries and found the total number of follicles ranged from 130,000 to 385,000 per ovary, with an average of 266,000 of which $95 \%$ being the primordial follicles. Charleston et al. ${ }^{3}$ studied 48 pair of normal human ovaries aging from 8 to 51 years and found the average number of non-growing follicles (NGF) 46,213 per ovary. Ahmed ${ }^{9}$ studied 62 ovaries and found the mean number of growing follicles of the right ovary and left ovary 13.59 and 15.00 in 2-13 years age, 14.68 and 15.66 in 1445 years age and 9.57 and 9.25 in 46-80 years age group respectively in Bangladeshi cadavers. Hansen et al. ${ }^{18}$ studied normal human ovaries collected from 122 women aging from 0-51 years and found the mean number of non-growing follicle 130286. The findings of the present study are slightly higher than that of Ahmed ${ }^{9}$, but much lower than that of Forabosco et al. ${ }^{17}$, Charleston et al. ${ }^{3}$, Hansen et al. ${ }^{18}$. The difference in follicular number of this study may attribute to technical difference in procedure and racial variation. 


\section{Conclusion}

In the present study, the average diameter of Graafian follicle was found greater in the right ovary than that of the left. Moreover, it was also found that the number of ovarian follicles decreases in old age. Further studies with larger sample and high technical backup are recommended.

\section{Acknowledgement}

We would like to express our sincere gratitude to the authority of Health, Nutrition \& Population Sector Programme (HNPSP) of Directorate General of Health Services (DGHS) of the Government of the People's Republic of Bangladesh, and Principal, Dhaka Medical College, Dhaka, for the research grant to support this study.

\section{Author affiliations}

1. Dr. Hosna Ara Perven, Assistant Professor, Department of Anatomy, The Medical College for Women \& Hospital, Uttara, Dhaka.

*2. Dr. Abu Sadat Mohammad Nurunnabi, Lecturer, Department of Anatomy, Dhaka Medical College, Dhaka.

3. Dr. Shamim Ara, Professor and Head, Department of Anatomy, Dhaka Medical College, Dhaka.

*For correspondence: Dr. Abu Sadat Mohammad Nurunnabi, Lecturer, Department of Anatomy, Dhaka Medical College, Dhaka. Cell Phone: +8801712290608 , Email:shekhor19@yahoo.com

*For correspondence

\section{References}

1. Guyton AC, Hall JE. Female physiology before pregnancy and female hormones. In: Text book of medical physiology. $11^{\text {th }}$ ed. New Delhi: Elsevier; 2006. p.1011-25.

2. Sforza C, Vizzotto L, Ferrario VF, Forabosco A. Position of follicles in normal human ovary during definitive histogenesis. Early Hum Dev 2003; 74(1): 27-35.

3. Charleston JS, Hansen KR, Thyer AC, Charleston LB, Gougeon A, Siebert JR, et al. Estimation human ovarian non-growing follicle number: the application of modern stereology techniques to an old problem. Hum Reprod 2007; 22(8): 2103-10.

4. Miller PB, Charleston JS, Battaglia DE, Klein NA, Soules MR. Morphometric analysis of primordial follicle number in pigtailed monkey ovaries: symmetry and relationship with age. Biol Reprod 1999; 61(2): 553-6.

5. Myers M, Britt KL, Wreford NGM, Ebling FJP, Kerr JB. Methods for quantifying follicular numbers within the mouse ovary. Reproduction 2004; 127: 569-80.

6. Gougeon A. Dynamics of follicular growth in the human: a model from preliminary results. Hum Reprod 1986; 1(2): 81-87.

7. Healy JC. Female reproductive system. In: Stranding S, Borley NR, Collins P, Crossman AR, Gatzoulis MA, Healy JC, et al. eds. Gray's anatomy: the anatomical basis of clinical practice. $40^{\text {th }}$ ed. Edinburgh: Elsevier Churchill Livingstone; 2008. p.1293-9.

8. US Census Bureau. International Data Base, 2004.

9. Ahmed MS. Gross and histomorphological study of ovary in Bangladeshi cadaver. (MPhil thesis). Mymensingh: Mymensingh Medical College, University of Dhaka; 2007.

10. Kumar P, Malhotra N. eds. Jeffcoate's principles of gynaecology. $7^{\text {th }}$ ed. New Delhi: Jaypee; 2008. p.36.

11. Nurunnabi ASM, Mahbub S, Shahriah S, Begum GN, Ara S. Thyroid follicles and parenchyma are found to increase with advancing age during the first 50 years of life in Bangladeshi people. J Bangladesh Soc Physiol 2009; 4(2): 88-92.

12. Copenhaver WM, Kelly DE, Wood LR. The Female reproductive system. In: Bailey's text book of histology. $17^{\text {th }}$ ed. Baltimore: Williams \& Wilkins; 1978. p.645-59.

13. Bhatla N. ed. Jeffcoate's principles of Gynacecology. $6^{\text {th }}$ ed. London: Arnold; 2001. p.6089.

14. Fawcett DW. Bloom and Fawcett - a textbook of histology. 12 $2^{\text {th }}$ ed. New York: Chapman \& Hall; 2004. p.816-32.

15. Junqueira LC, Carneiro J. Basic histology. $11^{\text {th }}$ ed. Baltimore: Lippincott Williams \& Wilkins; 2005. p.449-56.

16. Ross MH, Pawlina W. Histology: a text and atlas with correlated cell and molecular biology. $5^{\text {th }}$ ed. Baltimore: Lippincott Williams \& Wilkins; 2006. p. $773-88$.

17. Forabosco A, Sforza C, De Pol A, Vizzotto L, Marzona L, Ferrario VF. Morphometric study of the human neonatal ovary. Anat Rec 1991; 231(2): 201-8.

18. Hansen KR, Knowlton NS, Thyer AC, Charleston JS, Soules MR, Klein NA. A new model of reproductive aging: the declinein ovarian nongrowing follicle number from birth to menopause. Hum Reprod 2008; 23(3): 699-708. 